\title{
Study on Risk Assessment of Meat and Meat Products Quality Safety Based on Risk Matrix
}

\author{
Xin Hai-hong \\ College of Quality and Technical Supervision \\ Hebei University \\ Baoding 071000,China \\ e-mail: xinhaihong498@163.com
}

Fang Xiao-qian

College of Quality and Technical Supervision

Hebei University

Baoding 071000,China

e-mail: 15100271135@163.com

\author{
Wang Yuan-yuan \\ College of Quality and Technical Supervision \\ Hebei University \\ Baoding 071000,China \\ e-mail: 15131277975@163.com
}

\author{
Hong Si-hui \\ College of Quality and Technical Supervision \\ Hebei University \\ Baoding 071000,China \\ e-mail: hongsihui1994@163.com \\ Wang Ting-xin \\ College of Quality and Technical Supervision \\ Hebei University \\ Baoding 071000,China \\ e-mail: tingxinwang@126.com
}

\begin{abstract}
In order to control the food safety risk about meat products effectively, the government supervision and spot check data need to be collected about meat products in recent years. Then unqualified occurrence circumstance of different-category meat product was analysed. On the combination of government supervision, illegal cases, food poisoning, consumer complaints and more digitals in other aspects, we identified food safety risk factors of meat products. This paper presents a food safety risk assessment model based on risk matrix. Taking bacon and jerky products for example to conduct an empirical study, the factor of food safety was valued different risk levels. It will be not only provide a basis for decision-making of government to plan and implement the replied measure of risk dynamically, but also provide a reference for other food categories in risk factor degree assessment of quality and safety.
\end{abstract}

Keywords-risk matrix; food safety; risk assessment; meat and meat products; government regulation

\section{INTRODUCTION}

With the rise of people's living standard, the requirement of Chinese meat products is increased. According to the "Five-Year-Plan", the Chinese meat production yield will attain to 15 million tons by 2015 . The rate of growth in 2015 is increasing by $25 \%$ than 2010. But in recent years, the security incidents of meat productions quality happened frequently, like overdue meat and BSE etc. That brought people fear to meat, and the needs of the consumers have no real release. China is a vast country of food. Depending on statistics, Chinese consume 4 billion catties of foods every day. It implies that each supervisor needs to supervise more than 30,000 foods every day. Besides, circulation of meat products in the food consumption ratio is big and food chain length, involving agricultural breeding and pretreating, production and processing etc, in which the breeding, production and processing link, and cooked meat market are the source and focus of the quality and safety of meat products. The government regulation plays an important role in purifying the market and enterprise management. In order to improve the pertinence and effectiveness, government should use the scientific method to carry out risk assessment and monitoring and control the quality and safety risk in limited government resources. This text will expound the import of the methods of risk matrix into risk evaluation and control of meat production.

\section{CURRENT SITUATION OF MEAT QUALITY}

By the quality of meat and meat products inspection standard knowable, meat and meat products inspection mainly include Frozen meat, modulation of cured meat products, fermented meat, smoked grilled meat, smoked and cooked ham sausage products, butter braised pork products and cooked dry products etc. The inspection items includes sensory, lead, arsenic, mercury, cadmium, etc, a total of 32 indicators. This text collected spot check data from 2011-2014 nationwidely, the unqualified rate statistics as showed in Fig .1, meat and meat products unqualified rate were steady between $3 \%-5 \%$, and showed growth after 2012.

In 2014 the national spot checks all kinds of meat products shown in Fig .2, The sauce braised pork products and jerky products, smoked and cooked sausage and ham in meat products unqualified accounts for more than $82.7 \%$, constitute the main source of unqualified meat products. 
All kinds of the discovery in 2014 of the national check in two stages of unqualified monitoring project statistics of various types of unqualified test items proportion as showed in Fig .3 and Fig .4.

In Fig .3, the total number of colonies in the second stage is unqualified for a drop in the first stage, but it still is the main cause of the unqualified meat products. Although the unqualified ratio of each index volatility changes over time to a certain extent, but in a certain period unqualified project still has guaranteed stability. For the quality of meat products safety risk identification, analysis and evaluation have important directional function. Fig .4 shows meat and meat products unqualified mainly comes from the total number of colonies exceed the standard, the rate of protein supply shortage, additives exceed the standard (such as: preservatives sorbic acid), coliforms, synthetic pigment exceed the standard.

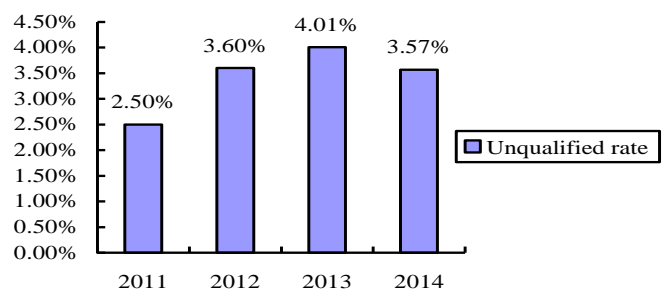

Figure 1. 2014 total unqualified number statistics

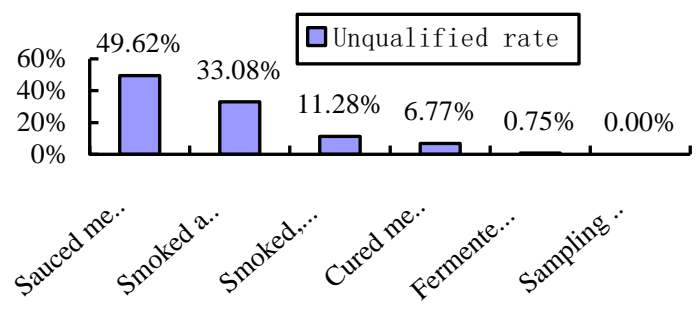

Figure 2. In 2014, Unqualified meat and meat products classification statistics
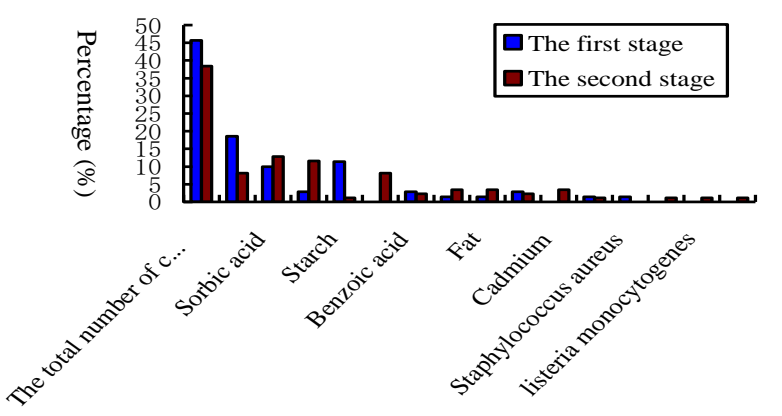

Figure 3. In 2014 the first two stages, selective examination

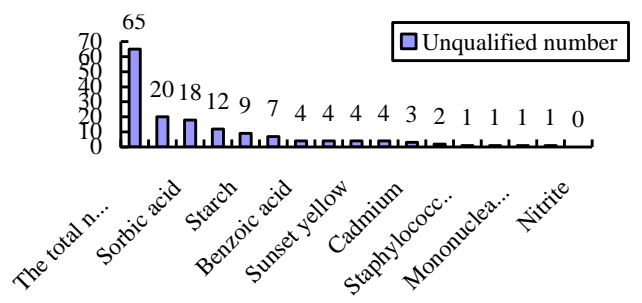

Figure 4. In 2014, each project total unqualified number
Although the number of food poisoning events since 2 011 decreased year by year, food poisoning has a huge social impact. In the world, by the calendar year st atistical reports of food poisoning, poisoning of meat and meat products ranks first. For example, in 2014 Chinese food poisoning the number of 4620, making up nearly $50 \%$ of the total number of poisoning in.

\section{RISK MATRIX MODEL AND COUNTERMEASURES}

Currently, the methods of the food risk safety valuation include more than 30 varieties, such as the Failure Mode and Effects Analysis (FMEA), the Delphi technique ${ }^{[2]}$, the Fault Tree Analysis (FTA), the Risk Matrix ${ }^{[3,4]}$.These methods have advantages and disadvantages. For the risk source of food safety is complicated, there are a lot of difficulties by completely qcuantitative methods. Risk Matrix presents a food safety risk assessment method which combines the result classification by qualitative and semi-quantitative method with the possibility of producing the specified risk. As a screening and verification tools in the food saftey realm, it can carry on the risk grade sorting and develop the applicable control measures and contribute to exchange risk and jointly understand risk qualitative grade. It is binary function of probability and severity. Expression:

$$
\mathrm{z}_{i}=\phi\left(x_{i}, y_{i}\right)=x_{i} \times y_{i}^{[5]}
$$

Note: $x_{i}$ is the possibility of hazard index $\mathrm{I} ; y_{i}$ is severity of hazard index I.

The model is used in meat and meat products safety risk monitoring and the risk only limits to the Food-borne risk and only involve to the harmful material.

The possibility's measurement is based on the exposed frequency of food. Because of diverse social circumstances, the size of the possibility is influenced by different factors. That makes measuring become difficult. While the exposed data in the government supervision cannot cover all food realms, sampling has limited representation. The unqualified rate in sampling inspection, the ratio of complaint, the ratio of food poisoning and the ratio of illegal case shows the size of the possibility of the different levels. For example, the unqualified rate in sampling inspection mainly focus on chemical and biological hazards in production; The ratio of complaint mainly emphasizes the relative probability of exposure biological and physical hazard; Illegal cases stree on the relative probability of adulterate, metamorphic in the validity period etc. Food-borne intoxication mainly involves living creature and chemistry harm. In addition to the unqualified rate generated in the production link, the remaining three generate complex reasons, can be traced back to the food chain each link, to consumers, dealers, restaurant operators, producers and suppliers of raw materials more responsibility, such as improper, consumer food service operators, production enterprises ect. All those problems are caused by complicated reasons. Moreover the four indexes and the media exposure related. Between each index, there must have some relativity. When it has a big possibility to happen at any or several of indexes in a same stage. Then it can judge to have a greater possibility in response to the risk occurrence. Reference meat and meat productions' 
supervision data during the recent three years from Chinese official release, this text determined the rating criteria of the risk item occurrence possibility for the meat and meat productions, as TABLE ${ }^{[6]}$.

The severity measurement takes the influence of consumers' health, out-of-gauge degree of risk project and sensitivity to the special group into consideration to confirm harmful degree. The severity should be determined according to the tallest grade of items in these three dimensions. The criteria is shown in TABLE II .

According to the severity and the possibility of occurrence can determmine the risk level and the counter easures as showed in TABLE III.

\section{APPLICATION EXAMPLE}

Unqualified rate of pot stewed meat and dried meat products is higher in the regulation. Through the analysis of the food chain, we considered the relevant standards, and combined government supervision, media exposure and consumer complaints and other food hazard condition, identified the main risks, and carried on risk rank evaluation.
The process is to provide related information to 5 food experts who came from health departments, food and drug supervision and administration department and detection departments, food in spection departments and so on. According to table 2 and table 3 criteria, we adopted Delphi method. After experts judged at least three times, and the average value is results. With the total number of colonies as an example, the basis of judgment on possibility: national sampling unqualified rate was $1.7 \%$, we could determine the score value in the range of $[4,5]$ and mean values of 5 experts score was 4.7; The basis of judgment on severity: for causing death or acute poisoning of group events didn't appear and the sensitivity of special groups weren't prominent, compare the total number of colonies regulation exceed the standard measurement of all the data of average value with the maximum value and the limited value comparison, the average value of the experts evaluation results was 3.6. Risk rating score was 17.08 which was a high risk. The rest of risk level assessment results was shown in TABLE IV.

TABLE I . XI POSSIBILITY RATING CRITERIA

\begin{tabular}{|c|c|c|c|c|c|c|}
\hline \multirow{2}{*}{ Level } & \multirow{2}{*}{$\begin{array}{l}\text { Possibility } X_{\mathrm{i}} \\
\text { (Continuous ) }\end{array}$} & \multirow{2}{*}{$\begin{array}{l}\text { Qualitative } \\
\text { Description }\end{array}$} & \multicolumn{4}{|c|}{$\begin{array}{c}\text { In Four Dimensions, Use The Highest Dimension To Grade At } \\
\text { Quantificational Possibility Judgement }\end{array}$} \\
\hline & & & $\begin{array}{l}\text { Unqualified } \\
\text { Fraction }\end{array}$ & $\begin{array}{c}\text { Proportion of } \\
\text { complaint }\end{array}$ & $\begin{array}{c}\text { Proportion of } \\
\text { foodpoisoning }\end{array}$ & $\begin{array}{c}\text { Proportion of } \\
\text { illegal cases }\end{array}$ \\
\hline 5 & $(4,5]$ & Frequent & above $1.5 \%$ & more than $8 \%$ & more than $6 \%$ & more than $1.2 \%$ \\
\hline 4 & $(3,4]$ & More & above $1 \%$ & more than $6 \%$ & more than $4 \%$ & more than $0.9 \%$ \\
\hline 3 & $(2,3]$ & Occasional & above $0.5 \%$ & more than $4 \%$ & more than $2 \%$ & more than $0.6 \%$ \\
\hline 2 & $(1,2]$ & Less & above $0.1 \%$ & more than $2 \%$ & more than $1 \%$ & more than $0.3 \%$ \\
\hline 1 & {$[0,1]$} & Very few & $0 \%$ & less than $2 \%$ & less than $1 \%$ & less than $0.3 \%$ \\
\hline \multicolumn{7}{|c|}{$\begin{array}{l}\text { Among them: } 1 \text { the fraction of sampling batch=the unqualified batch number/the total batch number of sampling certain types of food; } 2 . t \text { he } \\
\text { complaint ratio= the quantity of certain food complaint/ quantity of all food complaints; } 3 \text {. the ratio of food poisoning= certain types of food } \\
\text { poisoning cases number / all cases number of food poisoning; } 4 \text {. illegal cases ratio= the illegal cases number for certain kinds of food / the total } \\
\text { number of food illegal cases. } \\
\text { Note: Possibility boundaries can be adjusted dynamically according to the result of government supervision and government food regulatory } \\
\text { requirements }\end{array}$} \\
\hline
\end{tabular}

TABLE II . YI SERVERITY RATING CRITERIA

\begin{tabular}{|c|c|c|}
\hline \multirow[t]{2}{*}{ Level } & \multirow{2}{*}{$\begin{array}{l}\text { Severity } \mathbf{Y}_{\mathbf{i}} \\
\text { (Continuous) }\end{array}$} & $\begin{array}{c}\text { In Three Dimensions, The Highest Dimension To Grade At Quantificational Severity } \\
\text { Judgement }\end{array}$ \\
\hline & & Description \\
\hline 5 & $(4,5]$ & $\begin{array}{l}\text { 1)Lead to death or mass of acute poisoning ;2)Serious exceed the standard; 3)The special group } \\
\text { has very strong sensitivity }\end{array}$ \\
\hline 4 & $(3,4]$ & $\begin{array}{l}\text { 1)Cause unrecoverable damage (disability) or by groups of mild poisoning ;2)The more serious } \\
\text { exceed the standard ;3)The special group has strong sensitivity }\end{array}$ \\
\hline 3 & $(2,3]$ & $\begin{array}{l}\text { 1)Lead to moderate harm, in the long-term, recovery; 2)Exceed the standard ;3)The sensitivity } \\
\text { of special groups in general }\end{array}$ \\
\hline 2 & $(1,2]$ & $\begin{array}{l}\text { 1)Lead to slight harm, short-term can be restored; 2)Slightly exceed the standard; 3)A special } \\
\text { group of low sensitivity }\end{array}$ \\
\hline 1 & {$[0,1]$} & 1) No harm; 2)Reaches the limit value; 3) Not sensitive to special groups \\
\hline
\end{tabular}

TABLE III. THE RISK LEVEL

\begin{tabular}{|c|c|c|l|}
\hline Level & Scoring Range & The Risk Level & \multicolumn{1}{c|}{ Coping Measures } \\
\hline I & {$[10,25]$} & High-risk & $\begin{array}{l}\text { Analyze reasons and main production link, strengthen the supervision and organize special } \\
\text { inspection, to strengthen the monitoring frequency, sampling coverage increased by 50\%. }\end{array}$ \\
\hline II & {$[5,10)$} & Medium risk & $\begin{array}{l}\text { Organize special inspection, increase the monitoring frequency, sampling coverage increased } \\
\text { by 30\%. }\end{array}$ \\
\hline III & {$[1,5)$} & Low risk & Appropriate to reduce the monitoring frequency and the sampling coverage \\
\hline
\end{tabular}


TABLE IV.THE RISK ASSESMENT OF POT STEWED MEAT AND DRIED MEAT PRODUCTS

\begin{tabular}{|c|c|c|c|c|c|}
\hline Risk Factors & Risk Project Subdivisions & $\mathbf{X}$ & $\mathbf{Y}$ & $\mathbf{Z}$ & $\begin{array}{c}\text { Risk } \\
\text { Level }\end{array}$ \\
\hline \multirow{3}{*}{$\begin{array}{l}1 \text { Veterinary Drug Residues } \\
\text { over standard }\end{array}$} & Veterinary drugs(including sulfonamides; furans etc.) & 1.4 & 3.9 & 5.28 & Middle \\
\hline & Hormone & 2.0 & 2.0 & 3.93 & Low \\
\hline & Antibiotics & 2.0 & 3.0 & 5.97 & Middle \\
\hline \multirow{2}{*}{$\begin{array}{l}2 \text { Toxic chemical substances } \\
\text { Detection }\end{array}$} & Benzopyrene & 1.5 & 3.6 & 5.29 & Middle \\
\hline & Nitrite & 1.9 & 3.2 & 5.98 & Middle \\
\hline \multirow{2}{*}{3 Metal over standard } & Arsenic, Cadmium & 1.5 & 3.4 & 5.05 & Middle \\
\hline & $\begin{array}{l}\text { Aluminium } \\
\end{array}$ & 1.7 & 3.3 & 5.74 & Middle \\
\hline \multirow{4}{*}{4 Additive over standard } & Colorant(including sun set yellow, fancy red, carminum etc.) & 2.7 & 3.6 & 9.84 & Middle \\
\hline & Thickener(including starch、stab cloud solid gum etc.) & 3.8 & 3.4 & 12.79 & High \\
\hline & Preservative(including sorbic acid, benzoic acid etc.) & 4.0 & 4.0 & 16.00 & High \\
\hline & Antioxidant(including tea polyphenols, butylated hydroxyanisole etc.) & 1.9 & 2.8 & 5.32 & Middle \\
\hline \multirow{3}{*}{$\begin{array}{l}5 \text { Physical and chemical quality } \\
\text { characteristics non-reaching } \\
\text { standard }\end{array}$} & Protein supply rate non-reaching standard & 1.8 & 2.5 & 4.50 & Low \\
\hline & Fat contentnon-reaching standard & 2.1 & 2.0 & 4.27 & Low \\
\hline & Peroxide number non-reaching standard & 3.0 & 3.2 & 9.49 & Middle \\
\hline \multirow{2}{*}{6 Bacteria over standard } & Total numbers of colony & 4.7 & 3.6 & 17.08 & High \\
\hline & Coli group & 4.4 & 3.6 & 15.84 & High \\
\hline $\begin{array}{l}7 \text { Pathogenic bacteria over } \\
\text { standard }\end{array}$ & Staphylococcus aureus, salmonella, shigella etc. & 2.2 & 3.5 & 7.77 & Middle \\
\hline 8 Toxin detection & Cholalic acid, inner cholalic acid, yellow aspergillus toxin etc. & 1.0 & 3.9 & 4.00 & Low \\
\hline 9 Foreign body Detection & Soft: Hair insect etc. Sand; hard: wire, cullet, plastic packaging etc. & 1.7 & 2.6 & 4.48 & Low \\
\hline 10 Label violation & $\begin{array}{l}\text { Misleading of vague, ncomplete, inconsistent with the practical } \\
\text { content mark }\end{array}$ & 2.5 & 3.0 & 7.32 & Middle \\
\hline 11 False label & Shoddy as the spurious; false brand etc. & 3.2 & 3.6 & 11.40 & High \\
\hline $\begin{array}{l}12 \text { Hazardous substances } \\
\text { transfer in packaging }\end{array}$ & Heavy metal, phthalate clall, bisphenol A (BPA) etc. & 1.9 & 4.4 & 8.46 & Middle \\
\hline \multirow{2}{*}{$\begin{array}{l}13 \text { Illegal additive substance } \\
\text { detection }\end{array}$} & Aquae hydrogenii dioxide, formalin & 1.9 & 3.6 & 6.78 & Middle \\
\hline & Magdala red, Clenbnterol hydrochloride & 2.4 & 3.6 & 8.56 & Middle \\
\hline 14 Other illegal events & $\begin{array}{l}\text { Mad cow disease,Dioxin incident,Shoddy as the spurious and the } \\
\text { genuine }\end{array}$ & 2.0 & 2.7 & 5.33 & Middle \\
\hline
\end{tabular}

Different risk grading were showed in TABLE IV.

For example, high risk factors in the risks project included bacteria (total numbers of colony, coli group) number and preservative( including sorbic aci, benzoic acid etc.)beyond the standards and so on. Middle risk factors were veterinary drug residues over standard (including sulfonamides, furans etc) and others. Low risk factors were hormone and toxin detection etc.

According to the severity and the possibility of occurrence, we can determmine the risk level as TABLE IV and the counter measures as showed in TABLE III. Through targeted supervision and the dynamic adjustment of regulatory plan, the reasonable allocation of supervision power, risk grade can be reduced.

\section{CONCLUSION}

Although the risk matrix method for food safety risk evaluation is relatively rough, it is based on the experience of experts evaluation by quantitative and qualitative methods, this is an easy and effective method. It can provide the basis for government regulation. For government supervision and testing resources is limited and meat products category is complex, hazard index is tremendous. Based on the prediction of possible hazard, the effective use of the data exposured in the early supervision stage can reduce the arbitrariness. On high-risk pollutant index by increasing risk hidden perils and formulate the emergency response plan, the problem can be resolved in the bud and the risk can be controlled at the start. So it has the oretical and application value in the aspects of food safety risk control.

\section{ACKNOWLEDGMENT}

This work was financially supported by the Hebei soft science research plan (14456213D)

\section{REFERENCES}

[1] Zhu Ming. Food safety and quality control, Bei Jing: Chemical Industry Press, 2008.

[2] Han Lu. Delphy, Shanghai educational evaluation,vol.1, 2014.

[3] External Moisture: A Guide to Using the Risk Matrix,New Zealand Government - Department of Building \& Housing, 2005.

[4] Liu Qing Jun, Ting Chen, Jing Hua Zhang, and Tan Wang. Food safety risk is monitoring model based on risk matrix, Food Science, vol.5, 2010, pp.86-90.

[5] Huang Xiao Juan, and Bei Lin Liu. The food safety risk early warning index system design and research, Journal of Harbin University of Commerce(Natural Sciences Edition),vol.5, pp.621-629, 2008.

[6] Liao Zhong Xing, and Jin Xi Wang. The methods applied in the import and export food safety risk assessment., Journal of Inspection and Quarantine, vol.6, 2013.

[7] Tully RJ, and Browne KD. Appraising the risk matrix 2000 static sex offender risk assessment tools, Int J Offender Ther Comp Criminol, No.2 Vol.59, 2015.

[8] Chen Yong Gang, Application of risk matrix in aviation repair of quality risk management, Industrial Engineering and Management,vol.1, 2014 pp.138-142.

[9] Wassan Rano Khan, Majid Mohd Amin Abd, and Mokhtar Ainul Akmar. Risk matrix model for rotating equipment MATEC Web of Conferences, Vol.13, 2014

[10] Zhou Ping Ping, Zhao Ping Liu, Lei Zhang, Ai Dong Liu, Yan Song, Ling Yong, and Ning Li. Methodology and application for health risk classification of chemicals in foods based on risk matrix, Biomed Environ Sci, Vol.27, 2014 